\title{
EXTRAÇÃO DE NUTRIENTES PELA VIDEIRA 'NIAGARA ROSADA' ENXERTADA EM DIFERENTES PORTA-ENXERTOS ${ }^{1}$
}

\author{
MARCO ANTONIO TECCHIO ${ }^{2}$, LUIZ ANTONIO JUNQUEIRA TEIXEIRA ${ }^{3}$, \\ MAURILO MONTEIRO TERRA ${ }^{2}$, MARA FERNANDES MOURA ${ }^{2}$, ERASMO JOSÉ PAIOLI-PIRES ${ }^{2}$
}

RESUMO - Objetivou-se avaliar a influência dos porta-enxertos 'IAC 766', 'IAC 572', 'IAC 313' e 'IAC 571-6' na extração de nutrientes pelos ramos removidos na poda e pela colheita dos cachos da videira 'Niagara Rosada', cultivada em Votuporanga, no Estado de São Paulo, Brasil. Realizou-se a poda de produção em 18-08-2009, em que avaliaram a massa fresca e a massa seca dos ramos, visando a estimar o acúmulo de biomassa pelos ramos da videira. Na colheita, estimou-se a produtividade pela pesagem dos cachos/planta e do número de plantas/ha. As amostras de ramos e cachos foram submetidas à análise química de nutrientes e, baseado no acúmulo de massa seca dos ramos e na produtividade, estimou-se a extração de nutrientes. Obteve-se, com o porta-enxerto 'IAC 572', maior extração de nutrientes pelos ramos. Referente aos cachos, obteve-se maior extração de nutrientes com o porta-enxerto 'IAC 766'. A extração diferencial de nutrientes pela 'Niagara Rosada', em função do porta-enxerto, pode servir como base para a adubação dos vinhedos. Termos para indexação: Vitis, nutrição mineral, porta-enxerto, extração.

\section{NUTRIENTS EXTRACTION BY VINE 'NIAGARA ROSADA' GRAFTED ON DIFFERENT ROOTSTOCKS}

\begin{abstract}
The objective was to evaluate the influence of rootstocks 'IAC 766', 'IAC 572', 'IAC 313' and 'IAC 571-6' on nutrient extraction by the branches removed by pruning, and bunches harvesting of 'Niagara Rosada', grown in Votuporanga, São Paulo state, Brazil. Pruning was done in 08/18/2009, when fresh and dry mass of branches were evaluated, aiming to estimate the biomass accumulation in the branches of the vine. At the harvest, the yield was estimated by the weight of clusters/plant and the number of plants/ha. Samples of branches and clusters were submitted to chemical analyses of nutrients and, based on the accumulation of dry mass of branches and the yield the extraction of nutrients was estimated. We observed for rootstock 'IAC 572' the higher extraction of nutrients by the branches. Referring to the extraction of nutrients by the clusters, we observed a higher extraction for the 'IAC 766'. The differential extraction of nutrients by 'Niagara Rosada' depending on the rootstock, can serve as a basis for the fertilization of the vineyards.
\end{abstract}

Index terms: Vitis, Mineral nutrition, rootstock, extraction, fertilization.

\section{INTRODUÇÃO}

No Brasil, o Estado de São Paulo destaca-se como o maior produtor nacional de uva para mesa, com aproximadamente 39 milhões de plantas e produção de 189,7 mil toneladas. As cultivares de uva comum para mesa, representada principalmente pela 'Niagara Rosada', correspondem a $89,1 \%$ do total de plantas e $49,1 \%$ da produção de uva no Estado de São Paulo. Na região noroeste do Estado, a Regional Agrícola de Jales responde por $2 \%$ da produção dessa variedade (Instituto de Economia Agrícola, 2011)

Nos últimos anos, notou-se forte tendência no aumento da área plantada dessa cultivar na região noroeste do Estado de São Paulo, em virtude do menor custo de produção e maior preço de revenda, quando comparado com as variedades de uva fina para mesa. Estima-se que, nessa região, a área plantada com 'Niagara Rosada' seja de 200ha. Infere-se que o melhor preço de revenda deve-se à época de colheita, realizada na entressafra da região

\footnotetext{
${ }^{1}$ Trabalho Sinfruit 011 - Simpósio Internacional de Fruticultura - Avanços na Fruticultura (17 a 21 Outubro) Apoio financeiro: FAPESP ${ }^{2}$ Pesquisador Científico do Centro de Frutas do Instituto Agronômico (IAC) - 13214-820 - Jundiaí, São Paulo, Brasil. Email: tecchio@ iac.sp.gov.br; mmterra@iac.sp.gov.br, mouram@iac.sp.gov.br, ejppires@iac.sp.gov.br.

${ }^{3}$ Pesquisador Científico do Centro de Solos e Recursos Ambientais do Instituto Agronômico (IAC) - 13012-970 - Campinas, São Paulo, Brasil. Email: teixeira@iac.sp.gov.br.
} 
sudoeste do Estado de São Paulo, considerada a região tradicional de cultivo.

Como em outras regiões vitícolas, o uso de porta-enxertos é uma prática obrigatória, por ter como principais objetivos o controle de pragas de solo, como a filoxera (Daktulosphaira vitifoliae Fitch, 1856), a pérola-da-terra (Eurhizococcus brasiliensis, Hempel, 1922) e nematoides; adaptação a diferentes tipos de solos; resistência a seca e/ou a excesso de umidade; precocidade de produção e aumento no vigor e produtividade da copa. Vários trabalhos foram realizados com o propósito de avaliar o comportamento da videira 'Niagara Rosada' sobre diferentes porta-enxertos, evidenciando a influência no crescimento vegetativo, produtividade, nas características dos cachos, na fenologia e nutrição da videira (PAULETTO et al., 2001; TERRA et al., 2003; MOTA et al., 2009).

Quanto aos aspectos nutricionais, sabe-se que os porta-enxertos apresentam grande variação em vigor, em consequência das diferentes exigências nutricionais e capacidade de absorção de água e nutrientes, pois suas raízes, em função das variedades, apresentam uma seletividade na absorção de íons da solução do solo. Inúmeros trabalhos na literatura relatam variações nos aspectos nutricionais da planta em função do porta-enxerto (ALBUQUERQUE; DECHEN, 2000; TECCHIO et al., 2007a; CSIKÁSZ-KRIZSICS;DIÓFÁSI; 2008; Miele et al., 2009). Tecchio et al. (2007a), em levantamento nutricional da videira 'Niagara Rosada', constataram que, com o porta-enxerto 'IAC 766', os teores foliares de $\mathrm{N}$ e K na 'Niagara Rosada' foram maiores quando comparado com o porta-enxerto 'Ripária do Traviú'. Miele et al. (2009), ao avaliarem o efeito de porta-enxertos no teor de nutrientes, em tecidos da videira 'Cabernet Sauvignon', obtiveram variações nos teores de N, P, K, Ca e Mg no limbo, pecíolo, ráquis e baga da videira 'Cabernet Sauvignon', sendo que este efeito variou em função do nutriente e do tecido considerado. Para o fornecimento balanceado de nutrientes, mediante a calagem e adubação, torna-se importante associar os resultados das análises químicas de solo e de folha com exportação de nutrientes pela poda e colheita dos cachos. Santos Neto (1973) relatou que, para a produção de $3,0 \mathrm{~kg}$ planta $^{-1}$ de uva 'Niagara Rosada' enxertada sobre 'Ripária do Traviú' $106-8 \mathrm{Mgt}$, a quantidade acumulada de nutrientes/frutos durante um ciclo de produção foi de 4,6g de N; 2,43g de $\mathrm{P} ; 13,8 \mathrm{~g}$ de K; $2,8 \mathrm{~g}$ de $\mathrm{Ca} ; 1,86 \mathrm{~g}$ de $\mathrm{Mg}$. Dechen (1979) verificou que, para a produção de $239,11 \mathrm{~g}$ de massa seca de cachos por planta, a quantidade de macro e micronutrientes acumulados pelos cachos da cv. Niagara
Rosada foi de: 2,8g de N; 1,1 de P; 7,5g de K; 0,39g de $\mathrm{Ca} ; 0,19 \mathrm{~g}$ de $\mathrm{Mg} ; 0,32 \mathrm{~g}$ de $\mathrm{S} ; 6 \mathrm{mg}$ de B; $2 \mathrm{mg}$ de $\mathrm{Cu} ; 17 \mathrm{mg}$ de $\mathrm{Fe} ; 35 \mathrm{mg}$ de $\mathrm{Mn}$ e $3 \mathrm{mg}$ de $\mathrm{Zn}$. O acúmulo total de nutrientes, em ordem decrescente, foi de $\mathrm{K}>\mathrm{N}>\mathrm{P}>\mathrm{Ca}>\mathrm{S}>\mathrm{Mg}>\mathrm{Mn}>\mathrm{Fe}>\mathrm{B}>\mathrm{Zn}>\mathrm{Cu}$. Hiroce et al. (1979) determinaram que, para produzir uma tonelada de uva 'Niagara Rosada', são extraídos do solo 879g de N; 292g de P; $1.890 \mathrm{~g}$ de $\mathrm{K}$; $95 \mathrm{~g}$ de Ca; $95 \mathrm{~g}$ de $\mathrm{Mg} ; 173 \mathrm{~g}$ de $\mathrm{S} ; 2,1 \mathrm{~g}$ de $\mathrm{B} ; 8 \mathrm{~g}$ de Cl; $0,6 \mathrm{~g}$ de $\mathrm{Cu} ; 3,0 \mathrm{~g}$ de $\mathrm{Fe} ; 2,5 \mathrm{~g}$ de $\mathrm{Mn} ; 3,0 \mathrm{mg}$ de $\mathrm{Mo}$ e $0,5 \mathrm{~g}$ de $\mathrm{Zn}$. Verificaram que a ordem decrescente de acúmulo foi $\mathrm{K}>\mathrm{N}>\mathrm{P}>\mathrm{S}>\mathrm{Ca}=\mathrm{Mg}>\mathrm{Cl}>\mathrm{Fe}>\mathrm{Mn}>\mathrm{B}>\mathrm{Cu}>\mathrm{Zn}>$ Mo.

Albuquerque e Dechen (2000) avaliaram a capacidade de absorção de macronutrientes nos porta-enxertos de videira 'IAC 313', 'IAC 572', 'IAC 766', 'Dog Ridge', 'Salt Creek' e 'Harmony'. Concluíram-se que a produção de biomassa apresenta alta correlação com a quantidade acumulada de nutrientes, sendo que o porta-enxerto 'IAC 572' apresentou acúmulo de matéria seca da parte aérea, extraindo maior quantidade de $\mathrm{N}, \mathrm{P}, \mathrm{K}$ e Ca, e igualando-se ao 'IAC 313' na extração de Mg. Tecchio et al. (2007b), em levantamento nutricional realizado em Jundiaí, avaliaram o acúmulo de nutrientes pelos cachos da videira 'Niagara Rosada' enxertada sobre os porta-enxertos 'Ripária do Traviú' e 'IAC 766'. Concluíram que a 'Niagara Rosada' apresentou maior acúmulo de $\mathrm{P}, \mathrm{Fe}$ e $\mathrm{Zn}$, enquanto sobre o porta-enxerto 'IAC 766' houve maior acúmulo de Mn. Em ambos os porta-enxertos, a 'Niagara Rosada' apresentou a seguinte escala de acúmulo de nutrientes pelos cachos, em ordem decrescente: $\mathrm{K}>\mathrm{N}>\mathrm{P}>\mathrm{Ca}>\mathrm{S}>\mathrm{Mg}>\mathrm{B}>\mathrm{Fe}>\mathrm{Mn}>\mathrm{Cu}>\mathrm{Zn}$.

Além do vigor do porta-enxerto, a origem do material genético também influencia no teor de nutrientes nos tecidos vegetais. Vercesi (1987) caracterizou a capacidade de absorção mineral do porta-enxerto em função da origem genética do material vegetativo utilizado.

Em condições de clima tropical, em que a videira é sustentada no sistema de pérgula, a exemplo do noroeste do Estado de São Paulo, não se encontram estudos relacionados à influência do porta-enxerto na extração de nutrientes pelos ramos e cachos, na cv. Niagara Rosada.

Este trabalho teve por objetivo avaliar a extração de nutrientes pelos cachos e ramos removidos pela poda da videira 'Niagara Rosada' enxertada em diferentes porta-enxertos, em Votuporanga, Estado de São Paulo, Brasil. Os dados de extração de nutrientes pelos cachos e ramos podem auxiliar na adubação de reposição realizada nos vinhedos. 


\section{MATERIAL E MÉTODOS}

$\mathrm{O}$ experimento foi realizado em vinhedo localizado no Polo Regional do Noroeste Paulista, em Votuporanga, no Estado de São Paulo, Brasil. A área experimental situa-se a $20^{\circ} 15^{\prime} \mathrm{S}$. e $50^{\circ} 30^{\prime} \mathrm{O}$. e $483 \mathrm{~m}$ de altitude, apresentando como indicadores climáticos precipitação pluvial anual média de $1.312 \mathrm{~mm}$ e temperatura média mensal de $23,6^{\circ} \mathrm{C}$.

$\mathrm{O}$ vinhedo experimental estava sustentado no sistema de pérgula, no espaçamento de 2,0 x 2,0m, com plantas de 4 anos de idade. Os tratamentos consistiram na combinação da cv. Niagara Rosada sobre os porta-enxertos 'IAC 766', 'IAC 572', 'IAC 313' e 'IAC 571-6'. O delineamento estatístico utilizado foi em blocos inteiramente casualizados, com 4 tratamentos, representados pelos porta-enxertos, 10 blocos e 4 plantas por parcela experimental. Os porta-enxertos IAC 766 (106-8 Mgt x Vitis caribaea), IAC 572 (Vitis caribaea e RR 101-14 Mgt), IAC 313 (Golia x V. cinerea) e IAC 571-6 (Vitis caribaea x Pirovano 57) foram obtidos por Santos Neto, no programa de melhoramento genético do Instituto Agronômico de Campinas (IAC). Apresentam como principais características alto: vigor vegetativo, ótimo enraizamento das estacas e aptos às condições subtropicais e tropicais do Brasil.

Realizou-se a poda de produção, com 6 a 8 gemas, no dia 18 de agosto de 2009. Após a poda, utilizou-se Dormex a 5\%, visando à uniformidade da brotação. Obteve-se a massa fresca total dos ramos removidos pela poda de cada parcela experimental. Posteriormente, amostras de 2 ramos por planta foram levadas ao laboratório, sendo submetidas à lavagem e secagem em estufa com circulação forçada de ar, visando à obtenção da porcentagem de massa seca dos ramos da amostra. Assim, estimou-se o acúmulo de biomassa pelos ramos da videira, multiplicando-se a porcentagem de massa seca da amostra pela massa fresca total dos ramos podados. Posteriormente, realizou-se amostragem para análise química dos nutrientes nos ramos, determinando-se os teores de N, P, K, $\mathrm{Ca}, \mathrm{Mg}, \mathrm{S}, \mathrm{B}, \mathrm{Cu}, \mathrm{Fe}, \mathrm{Mn}$ e $\mathrm{Zn}$, segundo metodologia descrita por Malavolta et al. (1997). Mediante o produto dos teores de nutrientes pela massa seca dos ramos, estimou-se a exportação de nutrientes pela remoção do material podado, em cada parcela experimental.

Por ocasião da colheita, entre 9 e 24-122009, realizaram-se a contagem de cachos/planta e a avaliação da produtividade/planta, mediante a pesagem dos cachos de cada planta da área expe- rimental. Posteriormente, realizou-se a amostragem de 5 cachos por parcela. Estes cachos foram submetidos à lavagem, sendo posteriormente colocados em bandejas de alumínio, as quais permaneceram em estufa com circulação forçada de ar, com temperatura entre 75 e $85^{\circ} \mathrm{C}$, durante 10 dias, para a obtenção da porcentagem de massa da matéria seca dos cachos. Posteriormente, realizou-se a análise química de macro e micronutrientes, segundo metodologia descrita por Malavolta et al. (1997). A extração de nutrientes pelos cachos foi obtida multiplicando-se o teor de nutrientes pela massa seca total dos cachos colhidos de cada parcela experimental.

Com os dados obtidos, realizaram-se a análise de variância e o teste Tukey, a 5\% de significância.

\section{RESULTADOS E DISCUSSÃO}

Obteve-se a maior produtividade da videira 'Niagara Rosada' enxertada sobre o porta-enxerto 'IAC 766', com 28,8t ha' ${ }^{-1}$, diferindo significativamente apenas do porta-enxerto 'IAC 571-6', que apresentou a menor produtividade, de 19,6t ha-1 (Tabela 1). Não se encontram relatos na literatura a respeito da influência do porta-enxerto pela videira 'Niagara Rosada' cultivada na região noroeste do Estado de São Paulo, onde se utiliza o sistema de sustentação em pérgula. No entanto, em sistemas tradicionais de cultivo, com a videira sustentada no sistema de espaldeira, Pauletto et al. (2001) obtiveram maiores produções com os porta-enxertos 'IAC 313' e 'IAC 766', totalizando, respectivamente, 2,69 e 2,59 kg planta ${ }^{-1}$. Terra et al. (2003), ao avaliarem o comportamento da cv Niagara Rosada enxertada sobre 5 diferentes porta-enxertos, concluíram que os porta-enxertos 'IAC 313', 'IAC 766' e 'Traviú' apresentaram maior produção. Mota et al. (2009) avaliaram a produção e a composição química das bagas das cultivares Niagara Rosada e Folha-de-Figo sobre diferentes porta-enxertos, obtiveram maior produção de ambas as cultivares com o porta-enxerto 'IAC 572', apresentando, no entanto, menor relação SS/acidez, menor teor de antocianinas e de compostos fenólicos, e maior acidez.

O porta-enxerto 'IAC 572' induziu à videira 'Niagara Rosada' maior acúmulo de massa seca dos ramos (Tabela 1), diferindo significativamente apenas do porta-enxerto 'IAC 571-6'. Estes resultados estão de acordo com Albuquerque e Dechen (2000), que também obtiveram maior acúmulo de massa seca da parte aérea sobre o porta-enxerto 
'IAC 572', quando comparado aos porta-enxertos 'IAC 313', 'IAC 766', 'Dog Ridge', 'Salt Creek' e 'Harmony'. Pauletto et al. (2001) também obtiveram, com a cv. Niagara Rosada, massa dos ramos podados semelhante com os porta-enxertos 'IAC 766' e 'IAC 313'.

Obtiveram-se variações significativas nos teores de $\mathrm{N}, \mathrm{K}, \mathrm{Mg}$ e $\mathrm{Mn}$ nas amostras de ramos removidos pela poda da videira 'Niagara Rosada' (Tabela 2). Sobre o porta-enxerto 'IAC 766' observaram-se maiores teores de $\mathrm{N}$ e $\mathrm{Mg}$ nos ramos, diferenciando-se significativamente apenas do porta-enxerto 'IAC 313'. No entanto, sobre o porta-enxerto 'IAC 766', houve menor teor de K, quando comparado com as demais cultivares avaliadas, e teores de Mn semelhantes ao 'IAC 572', que também foram inferiores aos obtidos com o porta-enxerto 'IAC 571-6'. Referente aos cachos, verificou-se que os porta-enxertos proporcionaram variações significativas nos teores de $\mathrm{N}, \mathrm{K}$, $\mathrm{Ca}, \mathrm{Mg}, \mathrm{S}, \mathrm{Cu}, \mathrm{Mn}$ e $\mathrm{Zn}$. Os maiores teores de $\mathrm{N}$ nos cachos da videira 'Niagara Rosada' foram obtidos sobre o porta-enxerto 'IAC 766', diferenciando-se significativamente apenas quando enxertada no 'IAC 571-6'. Sobre o porta-enxerto 'IAC 572', a cv. Niagara Rosada obteve o maior teor de $\mathrm{K}$ e os menores teores de $\mathrm{Ca}, \mathrm{Mg}$, $\mathrm{Mn}$ e $\mathrm{Zn}$ nos cachos.

As variações obtidas nos teores de nutrientes, nos ramos e cachos da videira, devem-se, provavelmente, ao vigor e à origem genética dos porta-enxertos. Diferença nos teores de nutriente, em função do porta-enxerto, também foi verificada por Tecchio et al. (2007a) e Miele et al. (2009).

Houve influência significativa dos porta-enxertos na extração de nutrientes pelos ramos e cachos da videira 'Niagara Rosada' (Tabela 3). Estas variações devem-se ao efeito do porta-enxerto sobre a produtividade, massa seca de ramos removidos na poda (Tabela 1) e teores de nutrientes nos ramos e cachos (Tabela 2) da videira 'Niagara Rosada', tendo em vista que, no cálculo da extração de nutrientes, estes fatores são considerados.

Obteve-se com o porta-enxerto 'IAC 572' maior extração de macro e micronutrientes pelos ramos da cv. Niagara Rosada, diferenciando-se significativamente apenas do porta-enxerto 'IAC 571-6'. Não houve variações significativas apenas na extração de manganês e zinco pelos ramos. Albuquerque e Dechen (2000), avaliando a capacidade de absorção de macronutrientes em porta-enxertos de videira, também obtiveram maior acúmulo de nutrientes com o porta-enxerto 'IAC 572 ', extraindo maior quantidade de N, P, K e Ca. Referente aos cachos, obtiveram-se maior extração de macro e micronutrientes da videira 'Niagara Rosada' enxertada sobre o porta-enxerto 'IAC 766', apresentando valores semelhantes de N, K, P, $\mathrm{S}, \mathrm{Cu}, \mathrm{Fe}$ e $\mathrm{Zn}$, quando comparado com os porta-enxertos 'IAC 313' e 'IAC 572'.

A extração de nutrientes pela 'Niagara Rosada' apresentou, em ordem decrescente, a seguinte escala de extração de nutrientes: $\mathrm{N}>\mathrm{Ca}>\mathrm{K}>\mathrm{Mg}>\mathrm{P}>\mathrm{S}>\mathrm{Mn}>\mathrm{Fe}>\mathrm{Zn}>\mathrm{B}>\mathrm{Cu}$ nos ramos e $\mathrm{K}>\mathrm{N}>\mathrm{Ca}>\mathrm{P}>\mathrm{S}>\mathrm{Mg}>\mathrm{Mn}>\mathrm{Fe}>\mathrm{B}>\mathrm{Zn}>\mathrm{Cu}$ nos cachos.

Referente à extração de nutrientes pelos cachos, esses resultados concordam, em parte, com os obtidos por Dechen (1979), que obteve a seguinte ordem de extração de nutrientes: $\mathrm{K}>\mathrm{N}>\mathrm{P}>\mathrm{Ca}>\mathrm{S}>\mathrm{Mg}>\mathrm{Mn}>\mathrm{Fe}>\mathrm{B}>\mathrm{Zn}>\mathrm{Cu}$. Verificou-se que houve diferença apenas na ordem de extração do fósforo e do cálcio.

Considerando-se a extração total de nutrientes, obteve-se maior extração de macro e micronutrientes da cv. Niagara Rosada enxertada sobre o porta-enxerto 'IAC 766', apresentando valores semelhantes de $\mathrm{N}, \mathrm{K}, \mathrm{P}, \mathrm{Ca}, \mathrm{Mg}, \mathrm{S}, \mathrm{B}$ e $\mathrm{Cu}$, quando comparado aos porta-enxertos 'IAC 572' e 'IAC 313'. Não houve variações significativas dos porta-enxertos para a extração de ferro, manganês e zinco. Quanto à extração total de nutrientes removidos pelos ramos e cachos, obteve-se, em ordem decrescente: $\mathrm{K}>\mathrm{N}>\mathrm{Ca}>\mathrm{P}>\mathrm{Mg}>\mathrm{S}>\mathrm{Mn}>\mathrm{Fe}>\mathrm{Zn}>\mathrm{B}>\mathrm{Cu}$.

Verificou-se que a extração total de N, P, K, $\mathrm{Ca}, \mathrm{Mg}, \mathrm{S}, \mathrm{B}$ e $\mathrm{Cu}$, na videira 'Niagara Rosada' enxertada sobre o porta-enxerto 'IAC 766', foi 57\%, $39 \%, 32 \%, 34 \%, 47 \%, 42 \%, 40 \%$ e $48 \%$ superior, quando enxertada sobre o porta-enxerto 'IAC 5716'. Esses dados, associados à análise de solo, podem contribuir para a racionalização da calagem e adubação da videira 'Niagara Rosada'. 
TABELA 1 - Resultados médios da produtividade, em $t$ ha ${ }^{-1}$, e da massa seca dos ramos removidos pela poda, em kg ha ${ }^{-1}$, da videira 'Niagara Rosada' enxertada em diferentes porta-enxertos. Votuporanga, 2009.

\begin{tabular}{ccc}
\hline Porta-enxerto & Produtividade $\left(\mathbf{t ~ h a} \mathbf{~}^{-1}\right)$ & Massa Seca de ramos $\left(\mathbf{k g ~ h a} \mathbf{~}^{-1}\right)$ \\
\hline 'IAC 313' & $25,9 \mathrm{ab}$ & $2079 \mathrm{ab}$ \\
'IAC 572' & $22,1 \mathrm{bc}$ & $2573 \mathrm{a}$ \\
'IAC 571-6' & $19,6 \mathrm{c}$ & $1529 \mathrm{~b}$ \\
'IAC 766' & $28,8 \mathrm{a}$ & $2037 \mathrm{ab}$ \\
\hline CV (\%) & 19,9 & 26,2 \\
DMS & 5,9 & 659 \\
Teste F & $7,1^{* *}$ & $6,3^{* *}$ \\
\hline
\end{tabular}

Médias seguidas de letras diferentes na coluna diferem entre si, ao nível de 5\%, pelo teste de Tukey.

TABELA 2 - Resultados médios dos teores de nutrientes nos ramos removidos pela poda e nos cachos da videira 'Niagara Rosada' enxertada em diferentes porta-enxertos. Votuporanga, 2009.

\begin{tabular}{|c|c|c|c|c|c|c|c|c|c|c|c|}
\hline \multicolumn{12}{|c|}{ Teores de nutrientes nos ramos } \\
\hline Porta-enxerto & $\mathbf{N}$ & $\mathbf{K}$ & $\mathbf{P}$ & $\mathbf{C a}$ & Mg & $\mathbf{S}$ & B & $\mathbf{C u}$ & $\mathbf{F e}$ & Mn & Zn \\
\hline & \multicolumn{6}{|c|}{$\left(\mathrm{g} \mathrm{Kg}^{-1}\right)$} & \multicolumn{5}{|c|}{$\left(\mathrm{mg} \mathrm{Kg}^{-1}\right)$} \\
\hline 'IAC 313' & $8,1 \mathrm{~b}$ & $6,1 \mathrm{a}$ & 1,3 & 7,2 & $1,7 b$ & 0,9 & 13,2 & 7,1 & 64 & $378 \mathrm{ab}$ & 45 \\
\hline 'IAC 572' & $8,5 \mathrm{ab}$ & $6,0 \mathrm{a}$ & 1,4 & 7,2 & $1,9 \mathrm{ab}$ & 1,0 & 11,5 & 7,5 & 64 & $303 b$ & 47 \\
\hline 'IAC 571-6’ & $8,5 \mathrm{ab}$ & $6,0 \mathrm{a}$ & 1,5 & 7,5 & $1,9 \mathrm{ab}$ & 0,9 & 13,0 & 6,3 & 74 & $397 \mathrm{a}$ & 53 \\
\hline 'IAC 766' & $8,8 \mathrm{a}$ & $5,0 \mathrm{~b}$ & 1,4 & 7,0 & $1,9 \mathrm{a}$ & 0,8 & 12,6 & 6,1 & 66 & $304 b$ & 47 \\
\hline CV $(\%)$ & 4,7 & 9,5 & 9,1 & 8,0 & 7,0 & 11,3 & 11,2 & 27,5 & 18,5 & 19,7 & 23,4 \\
\hline DMS & 0,5 & 0,7 & 0,2 & 0,7 & 0,16 & 0,1 & 1,7 & 2,3 & 15,1 & 83,1 & 13,8 \\
\hline Teste F & $5,5^{* *}$ & $8,2 * *$ & $2,3^{\mathrm{NS}}$ & $1,2^{\mathrm{NS}}$ & $3,9 *$ & $2,3^{\mathrm{NS}}$ & $2,8^{\mathrm{NS}}$ & $1,3^{\mathrm{NS}}$ & $1,6^{\mathrm{NS}}$ & $5,3 * *$ & $0,9^{\mathrm{NS}}$ \\
\hline \multicolumn{12}{|c|}{ Teores de nutrientes nos cachos } \\
\hline Porta-enxerto & $\mathbf{N}$ & $\mathbf{K}$ & $\mathbf{P}$ & $\mathbf{C a}$ & Mg & $\mathbf{S}$ & B & $\mathbf{C u}$ & $\mathbf{F e}$ & Mn & Zn \\
\hline & \multicolumn{6}{|c|}{$\left(\mathrm{g} \mathrm{Kg}^{-1}\right)$} & \multicolumn{5}{|c|}{$\left(\mathrm{mg} \mathrm{Kg}^{-1}\right)$} \\
\hline 'IAC 313' & 7,9ab & $20,8 b$ & 1,1 & $1,5 \mathrm{a}$ & $0,6 a$ & 0,7 & 11,5 & $2,3 \mathrm{ab}$ & 23 & $45 a$ & $3,4 a$ \\
\hline 'IAC 572' & $8,7 \mathrm{a}$ & $23,1 \mathrm{a}$ & 1,1 & $1,1 b$ & $0,5 b$ & 0,7 & 11,7 & $2,9 a$ & 20 & $27 \mathrm{~b}$ & $2,5 b$ \\
\hline 'IAC 571-6’ & $7,1 b$ & $18,3 \mathrm{c}$ & 1,2 & $1,3 \mathrm{ab}$ & $0,5 \mathrm{ab}$ & 0,6 & 13,0 & $2,0 \mathrm{~b}$ & 24 & $42 a$ & $3,0 \mathrm{ab}$ \\
\hline 'IAC 766' & $8,7 \mathrm{a}$ & $18,0 \mathrm{c}$ & 1,3 & $1,4 a$ & $0,6 \mathrm{a}$ & 0,6 & 13,3 & $2,6 a b$ & 24 & $33 \mathrm{ab}$ & $2,7 \mathrm{~b}$ \\
\hline CV (\%) & 16,1 & 8,9 & 15,3 & 16,2 & 11,2 & 16,3 & 17,0 & 24,3 & 14,7 & 25,8 & 21,1 \\
\hline DMS & 1,6 & 2,2 & 0,2 & 0,3 & 0,07 & 0,1 & 2,6 & 0,7 & 4,1 & 11,6 & 0,7 \\
\hline Teste F & $3,6^{*}$ & $18,1 * *$ & $1,5^{\mathrm{NS}}$ & $7,9 * *$ & $7,9 * *$ & $3,1^{*}$ & $1,8^{\mathrm{NS}}$ & $4,5^{*}$ & $2,3^{\mathrm{NS}}$ & $7,0 * *$ & $4,9 * *$ \\
\hline
\end{tabular}

Médias seguidas de letras diferentes na coluna diferem entre si, ao nível de 5\%, pelo teste de Tukey. 
TABELA 3 - Resultados médios da extração de macro $\left(\mathrm{kg} \mathrm{ha}^{-1}\right)$ e micronutrientes $\left(\mathrm{g} \mathrm{ha}^{-1}\right)$ pelos ramos removidos pela poda e pelos cachos da videira 'Niagara Rosada' enxertada em diferentes porta-enxertos. Votuporanga, 2009.

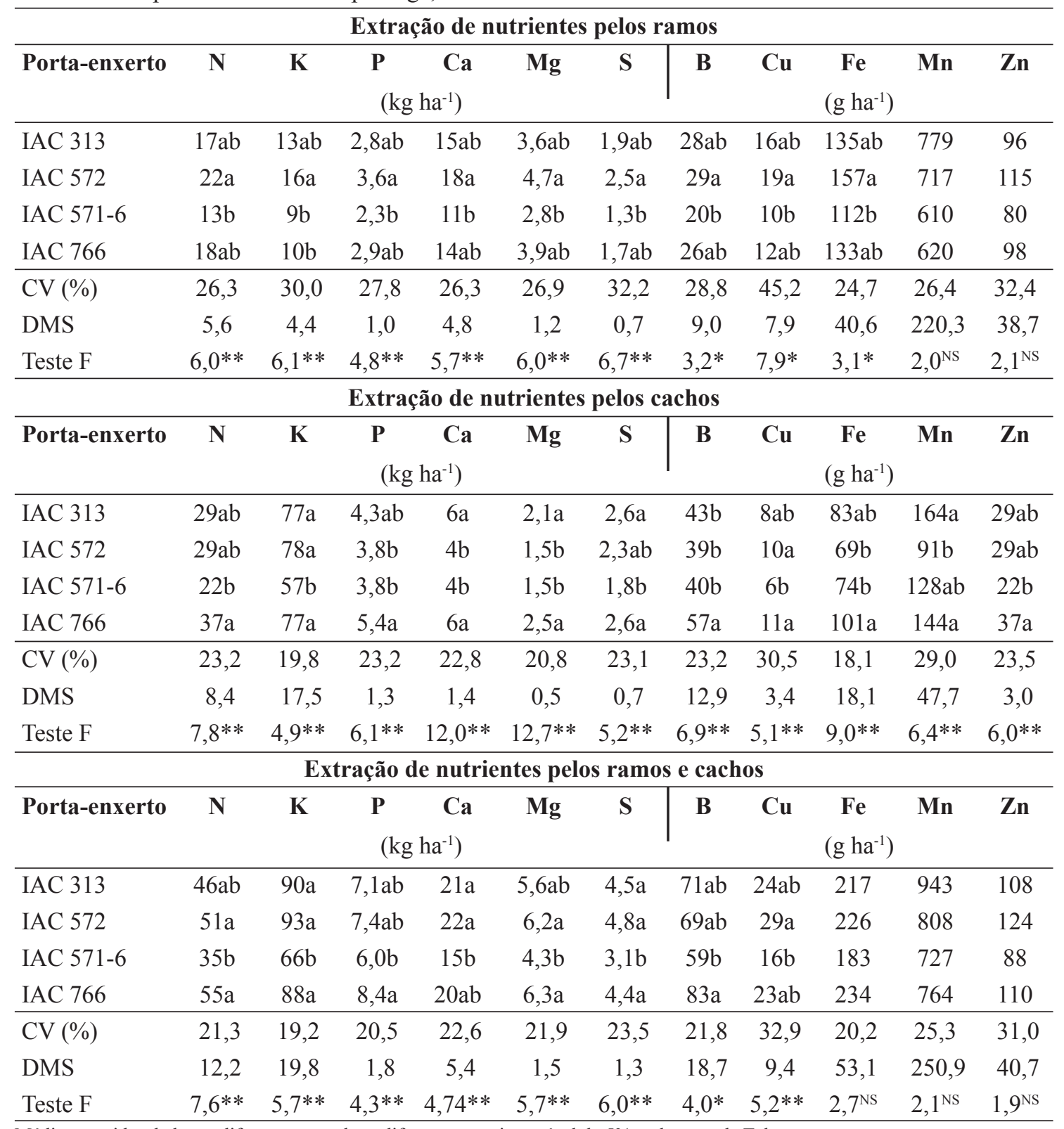

Médias seguidas de letras diferentes na coluna diferem entre si, ao nível de $5 \%$, pelo teste de Tukey.

\section{CONCLUSÃO}

Houve variações na extração de nutrientes pelos ramos e cachos da videira 'Niagara Rosada' em função do porta-enxerto. A proporção de nutrientes extraída pelos cachos e pelos ramos em relação à recomendação de adubação para videira, reforça a importância da adubação de manutenção realizada anualmente nos vinhedos.

\section{REFERÊNCIAS}

ALBUQUERQUE, T.C.S.; DECHEN, A.R. Absorção de macronutrientes por porta-enxertos e cultivares de videira em hidroponia. Scientia Agricola, Piracicaba, v. 57, n. 1, p. 135-139, 2000. 
CSIKÁSZ-KRIZSICS, A.; DIÓFÁSI, L. Effects of rootstock-scion combinations on macroelements availability of the vines- alany-nemesfajta kombinációk hatása a szőlő makroelem felvételére. Journal Central European Agricultures, v. 9, n. 3, p.495-504, 2008.

DECHEN, A. R. Acúmulo de nutritentes pela videira (Vitis labrusca L. x Vitis vinifera L.) cv. 'Niágara Rosada', durante um ciclo vegetativo. 1979. 133 f. Dissertação (Mestrado em Agronomia) Escola Superior de Agricultura "Luiz de Queiroz", Universidade de São Paulo, Piracicaba, 1979.

HIROCE, R.; GALLO, J. R.; BATAGLIA, O. C.; FURLANI, P. R.; FURLANI, A. M. C. Composição mineral e exportação de nutrientes pelas colheitas de frutos tropicais e temperados. In: CONGRESSO BRASILEIRO DE FRUTICULTURA, 5, 1979. Pelotas. Anais... Pelotas: Sociedade Brasileira de Fruticultura, 1979, p. 179-189.

INSTITUTO DE ECONOMIA AGRÍCOLA. Produção e número de plantas de videira no Estado de São Paulo. Disponível em: $<$ http:// www.iea. sp.gov.br>. Acesso em: 25 fev. de 2011.

MALAVOLTA, E.; VITTI, G. C.; OLIVEIRA, S. A. Avaliação do estado nutricional de plantas: princípios e aplicações. 2. ed. Potafós. Piracicaba. 319 p. 1997.

MIELE, A.; RIZZON, L. A.; GIOVANNINI, E. Efeito do porta-enxerto no teor de nutrientes em tecidos da videira 'Cabernet Sauvignon'. Revista Brasileira de Fruticultura, Jaboticabal, v. 33, n. 4, p. 1141-1149, 2009.

MOTA, R. V.; SOUZA, C. R.; FAVERO, A. C.; SILVA, C. P. C.; CARMO, E. L.; FONSECA, A.; REGINA, M. A. Produtividade e composição físico-química de bagas de cultivares de uva em distintos porta-enxertos. Pesquisa Agropecuária Brasileira, Brasília, v. 44, n. 6, p. 576-582, 2009.
PAULETTO, D.; MORÃO FILHO, F. A. A.; KLUGE, R. A.; SCARPARE FILHO, J. A. Produção e vigor da videira 'Niagara Rosada' relacionados com o porta-enxerto. Pesquisa Agropecuária Brasileira, Brasília, v. 36, n. 1, p. 115-121, 2001.

SANTOS NETO, J. R. A. A cultura da videira. Instituto Agronômico. Campinas (Boletim Técnico, 203). 1973.

TECCHIO, M. A.; PIRES, E. J. P.; TERRA, M. M.; MOURA, M. F. Produtividade e teores de nutrientes da videira Niagara Rosada em vinhedos nos municípios de Louveira e Jundiaí. Bioscience Journal, Uberlândia, v. 23, n.1, p. 48-58, 2007 (a).

TECCHIO, M. A.; PIRES, E. J. P.; TERRA, M. M.; TEIXEIRA, L. A. J.; LEORNEL, S. Características físicas e acúmulo de nutrientes pelos cachos de 'niagara rosada' em vinhedos na região de Jundiaí. Revista Brasileira de Fruticultura, Jaboticabal, v. 29, n. 3, p. 621-625, 2007 (b).

TERRA, M. M.; PIRES, E. J. P.; POMMER, C. V.; BOTELHO, R. V. Produtividade da cultivar de uva de mesa Niagara Rosada sobre diferentes porta-enxertos, em Monte Alegre do Sul - SP. Revista Brasileira de Fruticultura, v. 25. N. 3, p. 549-551, 2003

VERCESI, A. Gli assorbimenti radicali della vite: meccanismi e fattori influenti, Vignevini, v. 4, p.47$55,1987$. 